of the kind known to me was very imperfect in its details; it was revised for the next year, and since that time many lists, in one form or another, have been published. The figures for the animals with records of 2.25 , or better, are reasonably accurate; for the others there is much discrepancy. In the following table the numbers are my own, counting down to 1872 , inclusive ; the numbers after that date are derived from various lists published since that time in the sporing and breeding periodicals. From the very nature of t e case, the table cannot be accurate in the larger numbers, but the numbers do not lose their value for comparison with each other from such faults as to the details of the larger numbers, and, as such, it is undoubtedly the most significant series of numbers ever compiled to show progress in evolution, whether of a breed or species. The number of horses with records of 2.40 , or better, is now stated to be over five thou sand.

I leave it to mathematicians to plot the curves which immediately suggest themselves, and determine how fast horse's will ultimately trot, and when this maximum will be reached.

Table showing the numbers of Horses under the respective Records.

\begin{tabular}{|c|c|c|c|c|c|c|c|c|c|c|}
\hline & 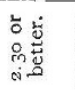 & 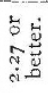 & 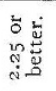 & 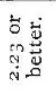 & 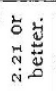 & 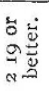 & 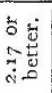 & 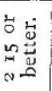 & 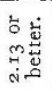 & 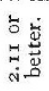 \\
\hline 1843 & I & & & & & & & & & \\
\hline I 844 & 2 & I & & & & & & & & \\
\hline I 849 & 7 & 2 & & & & & & & & \\
\hline 1852 & 10 & 3 & & & & & & & & \\
\hline 1853 & $x_{4}$ & 5 & & & & & & & & \\
\hline 1854 & 16 & 6 & & & & & & & & \\
\hline 1855 & 19 & 6 & & & & & & & & \\
\hline 1856 & 24 & 7 & I & & & & & & & \\
\hline 1857 & 26 & 7 & 2 & & & & & & & \\
\hline I858 & 30 & 7 & 2 & & & & & & & \\
\hline I859 & $3^{2}$ & 9 & 2 & I & I & & & & & \\
\hline 1860 & 40 & I I & 4 & 2 & $I$ & & & & & \\
\hline I86I & $4^{8}$ & 14 & 4 & 2 & I & & & & & \\
\hline 1862 & 54 & 17 & 7 & 4 & I & & & & & \\
\hline 1863 & 59 & 19 & 9 & 4 & I & & & & & \\
\hline I 864 & 66 & 22 & 12 & 4 & I & & & & & \\
\hline I 865 & 84 & 29 & 15 & 5 & 2 & I & & & & \\
\hline I866 & IOI & $3^{2}$ & I 7 & 6 & 3 & I & & & & \\
\hline I 867 & 124 & 42 & 21 & 9 & 5 & 2 & & & & \\
\hline I 868 & 146 & 52 & 28 & I3 & 6 & 2 & & & & \\
\hline 1869 & I7I & 63 & 34 & 15 & 10 & 4 & & & & \\
\hline 1870 & I94 & 72 & 35 & 16 & I I & 5 & & & & \\
\hline 1871 & 233 & 99 & 40 & 17 & I 2 & 6 & I & & & \\
\hline I 872 & 323 & - & - & - & - & - & - & & & \\
\hline 1873 & 376 & - & 74 & 28 & 15 & 5 & 2 & & & \\
\hline 1874 & 505 & - & 98 & 40 & 16 & I I & 5 & I & & \\
\hline 1875 & - & - & I 34 & $6 I$ & 30 & I 3 & 5 & 2 & & \\
\hline 1876 & 794 & - & 165 & $8 \mathrm{I}$ & 39 & 16 & 6 & 2 & & \\
\hline 1877 & 836 & - & 214 & 105 & 51 & 19 & 8 & 2 & & \\
\hline 1878 & $\mathrm{I}, 025$ & - & 270 & 129 & 68 & 24 & 9 & 4 & & \\
\hline 1879 & 1,142 & - & 325 & 164 & 88 & 33 & I I & 5 & I & \\
\hline 1880 & 1,210 & - & 366 & 192 & 106 & $4 \mathrm{I}$ & I 4 & 6 & 2 & I \\
\hline I 88 I & 1,532 & - & 419 & 227 & 126 & 49 & I5 & 7 & 2 & I \\
\hline 1882 & I, 684 & - & 495 & 275 & 156 & 60 & 18 & 8 & 2 & I \\
\hline
\end{tabular}

INSTITUTION OF MECHANICAL ENGINEERS

THIS Institution held their usual Spring meeting at the Institution of Civil Engineers, 25, Great George Street, on April II and I2, the president, Mr. Percy G. B. Westmacott, in the chair. Three papers were read, and discussed at length; a fourth, by Mr. A. C. Bagot, on "The Application of Electricity to Coal Mines," was postponed for want of time.

The nrst paper was by Prof. A. G. Greenhill, of Woolwich Arsenal, and dealt with the strength of shafting when exposed both to torsion and end-thrust. $\mathrm{He}$ has worked out for this case, by a complete mathematical investigation to be published in the Proceedings, the following formula :-

$$
\frac{\pi^{2}}{l^{2}}=\frac{l^{D}}{E I}+\frac{T^{2}}{4 E^{2} I^{2}}
$$

where $P=$ end-thrust, $T=$ twisting moment, $r=$ moment of inertia of cross-section, $E=$ modulus of elasticity, $l=$ maximum distance between bearings, which will allow a shaft to be stable.

When there is no twisting moment, as in a long column, the second part of the right-hand expression vanishes, and we have the ordinary formula of Euler. If there be no end-thrust, as in ordinary mill shafting, the first part vanishes. The special case where both occur together is that of the screw-shaft of a steamer; but here, it appears, on working the figures out with ordinary dimensions, that the second part is small in comparison with the first, and may be neglected. Hence a screw-shaft may so far be treated as if it were a long column only; and it follows at once that the numerous bearings interpo-ed between the engines and propeller (say, about every 25 feet) are quite unnecessary so far as stiffness is concerned. If retained, as seems desirable, simply to support the weight of the shaft, they might at least be made in some way elastic, so as to enable the shaft to accommodate itself to the sagging and straining of the vessel. It was, in fact, admitted on all hands that screw-shafts never give way from twist or thrust, but always by cross-breaking through strains induced by the unequal movements of the ship; and if so, there seems every reason for taking some steps at least in the direction which Prof. Greenhill indicates.

Another point which the paper touched upon was the question of hollow versus solid shafts. Now that shafts can be conveniently cast out of ingot steel, they are frequently made hollow, with the obvious advantage of increasing the stiffness as compared with the weight. Thus, in the case of the screw-shaft of the City of Rome, which is 25 inches diameter, with an internal hole of 14 inches diameter, it appears that the moment of inertia is 0.9 of that of an equal solid shaft, while the weight of the latter would be I 45 that of the former. Again, if a solid shaft were used of the same weight as the hollow shaft, or $20^{\circ} 7$ inches diameter, its moment of inertia, and therefore its stiffness, would be barely half that of the latter. Even if a transverse crack, I inch deep, were to occur in the hollow shaft (which it might be urged would place it at a serious disadvantage) the loss of stiffness comes out to be 6 per cent., whereas in a solid shaft of equal diameter the corresponding loss would be 5 per cent.; so that even here the advantage on the side of solidity is only I per cent.

These figures might seem to be conclusive, yet the solid shaft has its defenders. Mr. Edward Reynolds, of Messrs. Vickers and Co., stated roundly that the history of hollow screw-shafts was a mere history of disaster (whicb, however, was denied by a subsequent speaker); and he quoted some experiments of his own on shafts one-fourth the size of that in the City of Rome, where, tested under a $x$-ton weight falling from about 20 feet, the hollow shaft was rapidly destroyed, while the solid shaft remained uninjured. This occurred even when great care was taken to prevent the hollow shaft from getting flattened during the process. His explanation was that the comparatively unstrained fibres towards the centre of the section came in to support and relieve the exterior parts, whenever, by cracks or otherwise, these became unduly loaded. Prof. Kennedy, who followed, seemed to lean to the same view, and quoted the increase of stren th observable in the metal between the holes of a drilled plate, as being due, in some unexplained manner, to the influence of the unstrained metal behind the holes. A very satisfactory explanation of this fact was, however, given by Mr. Wrightson at the last meeting of the British 
Association. The real question to which Mr. Reynolds's tests point is probably how far theories which rest on the hypothesis that elasticity is perfect can properly be applied to cases where the breaking point has been nearly reached; and this is a question on which more light is very urgently needed, especially with reference to such cases as screw-shafts, where fractures, as a matter of fact, do very commonly occur.

The second paper, by Mr. W. Ford Smith, dealt with twist drills, milling machines, and other methods for the cutting and dressing of metal surfaces, which have been introduced within the last few years; and was almost entirely of a practical character. The third paper, by Mr. John Jameson, was on "Improvements in the Manufacture of Coke," and dealt with a new method, invented by the author, for recovering the gas, gas-tar, and ammoniacal liquor, which are separated from coking coal during the process of carbonisation. As the paper points out, these products are not originally present in the coal. There is, for instance, no ammonia in coal; but there are combinations containing nitrogen and hydrogen, and in almost any process of distillation parts of the evolved nitrogen and hydrogen unite, under very obscure conditions, to form ammonia, which, however, is not stable, but readily decomposes in the presence e.g. of oxygen. Every process of distillation, in fact (but some much more than others), favours the formation of gas on the one hand and of condensable hydrocarbons on the other. With regard to the former, its value in the neighbourhood of coke-ovens is not usually high, and it is a question whether it may not best be burnt in the oven itself, to furnish the heat required in any case for the distilling process ; but the value of tar and ammonia is great, and would probably not fall very low, even if the production were largely increased. At the same time, as a fuel they are not even equal to the same weight of pure carbon. It will be seen, therefore, that there is ample room for a process which will enable us to separate and utilise these by-products, instead of simply using them as fuel, or, which is far worse, discharging them unburnt to poison the air and destroy vegetation. Mr. Jameson's methnd of effecting this end is very simple. He takes an ordinary "beehive" coke-oven, makes it tolerably airtight by letting tar soak into the brickwork, and covers the floor wich an impervious substance, in which are inserted some large bricks or quarls, pierced with holes. Below these is a chamber connected with a pipe, which leads, through any convenient form of condenser, to a small exhausting fan. The oven is now charged and lighted from the top, to which alone air is admitted. The heat of combustion, penetrating downwards, gradually distils the pitch and gases out of the coal, and the fan being set to work, these products, instead of passing upwards to the fire, are sucked downwards through the holes in the floor, and afterwards separated, the tar being left in one condenser, the ammoniacal liquor in another, and the gas either used at once for steam-raising, \&c., or stored in a gas-holder till required.

In the discussion which followed, the advantage of saving the waste products was fully admitted, though some rather startling estimates of the author (who had assumed that $75,000,000 l$. per annum was practically wasted under our present system of coal consumption) were sharply criticised. But by the ironmasters who were present it was strongly laid down that the first duty of a coke-oven was to make good coke-such coke as would give the best results in a blast-furnace ; and that to this duty all consideration of by-products must give way. It was further suggested that pitch was a valuable ingredient in coke, and that this pitch was left in it by the present system, but withdrawn on the new one. This idea, however, seems to be founded on a misapprehension. $\mathrm{Mr}$. Jameson and others were able to state positively that the coke made by his process could not be distinguished in quality from the product of the old beehive oven; that the quantity per ton of coal was the same; and that the by-products, though differing very greatly in quantity according to the character of the coal, method of condensation, \&c., were almost always sufficient to repay, within a few months or even weeks, the $10 l$. or $15 l$. required to adapt an existing oven to the new arrangement. If these results are confirmed by more extended trials in different localities, the process seems likely, as one speaker phrased it, " to take a pretty prominent position among the great inventions of the present day."

\section{CORONERS' SCIENCE IN CHINA}

W HETHER Chinamen are or are not believers in the principle that it is better that nine guilty persons should escape rather than that one innocent person should suffer, they do at all events, by their manner of conducting inquests, leave open a wide door for the escape of murderers. A deeply-rooted repugnance to dissection of the human body and a consequently slight acquaintance with anatumy, coupled with an entire ignorance of the action of poisons, deprive coroners of every means of arriving at decisions except those furnished by outward symptoms and appearances. From early times, however, the importance attaching to human life has been recognised by the custom of holding inquests in cases of sudden death, and various works have been published embodying all the knowledge available on the subject to assist coroners in their duty of investigation. The best-known of these was the Se yuen luh, or "Record of the washing away of wrongs," which was given to the world in the thirteenth century, and which, under the same title, subsequently received the imprimatur of the officers of the Board of Punishments, who, in the exercise of their legislative function, issued it as a manual for coroners. In this work is expounded the whole system of Chinese medical jurisprudence, of which the following is a slight sketch.

One of the first directions given to coroners reminds one of Mrs. Glasse's celebrated dictum, and is to the effect that before issuing a warrant for an inquest they should be quite sure that there really is a corpse. This admonition is no less curious than the reason which makes it necessary. It appears to be not uncommon for unscrupulous swindlers to demand inquests on imaginary corpses for the purpose of extorting money from the wealthy owners of the houses where the bodies are said to be, who, rather than fall into the clutches of the law, generally pay the sum demanded on condition that all proceedings are stayed. But being well assured of the existence of a corpse, the coroner should proceed to the spot well provided with onions, red pepper, salt, white prunes, and vinegar with the lees. If death has just taken place, he should examine the top of the head, back of the ears, throat, and any other vital part where a sharp-pointed instrument may have been inserted. In case of his failing to find any such cause of death, he should interrogate the friends and neighbours, and then proceed to examine any wounds there may be on any other part of the person.

An infallible guide to the date of a wound is found in the colour of the bone affected. If it is a recent one or of a slight nature, the bone will be red, but if old and severe, the bone will be of a dark blue colour. Particular care should, however, be taken to as:ertain that these colours are genuine, and not manufactured to agree with the story told by the relatives. A red tint may be given to the bone by painting it with an ointment of genuine safflover, sapanwood, black plums, and alum, with the addition of boiling vinegar. On the other hand, green alum or nutgalls, mixed with vinegar, impart a dark blue or black hue. These counterfeit colours may, however, be distinguished by their want of brightness. Again, not uncommonly a fictitious wound is made after death by 